\section{Collection Efficiency and Capacity of Three Samplers for Acidic and Basic Gases}

CHUEN-JINN TSAI,*

CHENG-HSIUNG HUANG, AND

SI-HO WANG

Institute of Environment Engineering, National Chiao Tung

University, Hsin Chu, Taiwan

TUNG-SHENG SHIH

Institute of Occupational Safety and Health, Council of Labor Affairs, Taipei, Taiwan

This paper compares the collection efficiency and capacity of a coated porous metal disk with those of a silica gel tube and an impinger at the acid or basic aerosol concentration of two times the permissible exposure limitation (Taiwan IOSH, Institute of Occupational Safety and Health), relative humidity of $80 \pm 5 \%$, and temperature of $30 \pm 3^{\circ} \mathrm{C}$ in the laboratory. Using $5 \%$ sodium carbonate/ glycerin coating, the collection efficiencies of the porous metal disk for nitric acid, hydrogen chloride, and hydrogen fluoride are found to be higher than those of the silica gel tube and the impinger when the sampling time is less than $3.0 \mathrm{~h}$. The gas collection capacity of the porous metal disk coated with $5 \%$ sodium carbonate is calculated to be $3.9,5.8$, and $>2.5 \mathrm{mg}$ for nitric acid, hydrogen chloride, and hydrogen fluoride, respectively. For ammonia, the porous metal disk coated using $4 \%$ citric acid performs slightly better than the impinger, and the corresponding capacity is slightly greater than $33.6 \mathrm{mg}$.

\section{Introduction}

Inorganic acids are used extensively in various manufacture applications, including wet cleaning process in the semiconductor industry, forming and charging processes in the lead battery factory, electroplating processes, etc. Exposure to high concentration of acidic aerosolsand gases may result in detrimental effects on the respiratory system (1-3). The U.S. Occupational Safety and Health Administration (OSHA) has promulgated the concentration levels of these pollutants to which a worker may be exposed. Similar PEL (permissible exposure limit) levels for $\mathrm{HNO}_{3}, \mathrm{HCl}, \mathrm{HF}$, and $\mathrm{NH}_{3}$ adopted by Taiwan IOSH (Instituteof Occupational Safety and health) are 2, 5, 3, and 50 ppm by volume, respectively.

Simultaneous collection of six inorganic acids, including hydrofluoric $(\mathrm{HF})$, hydrochloric $(\mathrm{HCl})$, phosphoric $\left(\mathrm{HPO}_{3}\right)$, hydrobromic $(\mathrm{HBr})$, nitric $\left(\mathrm{HNO}_{3}\right)$, and sulfuric acids $\left(\mathrm{H}_{2-}\right.$ $\mathrm{SO}_{4}$ ), in a singlesilica gel sorbent tubeis described in National Institute of Occupational Safety and Health (NIOSH) M ethod 7903 (4). The collected sample is further analyzed by an ion chromatography. This method has been evaluated in the laboratory $(5,6)$, but the collection efficiency and capacity

* Corresponding author telephone: +886-3-5731880; fax: +8863-5727835; e-mail: cjtsai@cc.nctu.edu.tw.

2572 - ENVIRONMENTAL SCIENCE \& TECHNOLOGY / VOL. 35, NO. 12, 2001 of different acidic and basic aerosols remains to be studied. For samplingammonia gas, both Taiwan IOSH (7) and OSHA (8) employ an impinger that use $\mathrm{H}_{2} \mathrm{SO}_{4}$ as absorbingsolution. In this study, experiment for sampling acidic gases using the impinger, which contained basic $\mathrm{NaOH}$ absorbing solution, was also conducted.

Because of the hot and humid climate in Taiwan, the conditions of $80 \%$ relative humidity $(\mathrm{RH})$ and $30^{\circ} \mathrm{C}$ were chosen as the test conditions in the standard certifying procedure for a reference sampling and analysis method of the Tai wan IOSH (9). There is a need to re-evaluate different samplersin the hot and humid environment for theinorganic acids sampling in the workplace, where most traditional samplers have not been fully tested. At high humidity, absorption of water by the silica gel may influence its sampling efficiency of acidic gases. At high temperature, evaporation of absorbing liquid may influence the sampling efficiency of the impinger.

A diffusion denuder is a sampler that collects vapors and particles separately. Gas or vapor molecules diffuse rapidly to the wall of a diffusion sampler and are adsorbed onto the wall coated with a suitable material. The gas and particle concentration can further be determined by analyzing the extracts of the collected samples (10-14). Pui et al. (12) designed a compact coiled denuder whose performance is comparable to that of an annular denuder (11). Wai et al. (14) developed a high efficiency compact diffusion denuder using porous metal disks. Thesmall size of the denuder makes it possible to design a compact atmospheric and/or indoor denuder sampling system. Using $1 \%(\mathrm{w} / \mathrm{v}, \mathrm{g} / \mathrm{mL})$ sodium carbonate/ $1 \%(\mathrm{w} / \mathrm{v})$ glycerol coating in the porous metal disk, the collection efficiencies of $\mathrm{SO}_{2}$ and $\mathrm{HNO}_{3}$ were found to be higher than $99 \%$ and $93 \%$ at $10 \mathrm{~L} / \mathrm{min}$, respectively. If $2 \%$ sodium carbonate/ $1 \%$ glycerol coating was used, the gas collection capacity of the porous metal disk was as high as $8.4 \mathrm{mg}$ for $\mathrm{SO}_{2}$ (14). However, the collection efficiency and capacity have not been determined for other gases.

In this study, three sampling methods including the porous metal disk (o.d., $1.2 \mathrm{~cm}$; pore size, $100 \mu \mathrm{m}$; thickness, $0.317 \mathrm{~cm}$; P/N 1000, Mott Inc., Farmington, USA), the silica gel tube (SKC 226-10-03, SKC, Inc.), and the 100-mL impinger (from Merck Taiwan Ltd.) for sampling $\mathrm{HNO}_{3}, \mathrm{HCl}, \mathrm{HF}$, and $\mathrm{NH}_{3}$ werecompared for thecollection efficiency and capacity at two times the PEL promulgated by Taiwan IOSH, $80 \pm 5 \%$ $\mathrm{RH}$, and $30 \pm 3^{\circ} \mathrm{C}$.

\section{Experimental Methods}

Figure 1 shows the test setup to measure the gas collection efficiency of three acidic aerosol samplers for $\mathrm{HNO}_{3}, \mathrm{HCl}$, or HF gas. Desirable test gas concentration was generated by aerating clean air through a bubbler containing a known concentration of acidic solution. A hot plate was used to heat up the bubbler to facilitate gas generation. To generate $\mathrm{NH}_{3}$ gas, a standard gas bottle was used instead. The test gas was then mixed in a mixing bottle with humid air coming from a humidifier (also a bubbler) containing deionized water. Heating tape was used throughout the sampling line to prevent gas condensation on the wall. By adjusting the concentration of bubbling liquid, the hot plate temperature, and the flow rate of the mixing humid air, it was possible to obtain the desirable test gas concentration at two times the $\mathrm{PEL}, 30 \pm 3^{\circ} \mathrm{C}$, and $80 \pm 5 \% \mathrm{RH}$.

A quartz filter was used to collect small particlesthat might be generated in the test system before introducing the test gas to the samplers. There were three sampling lines: silica 


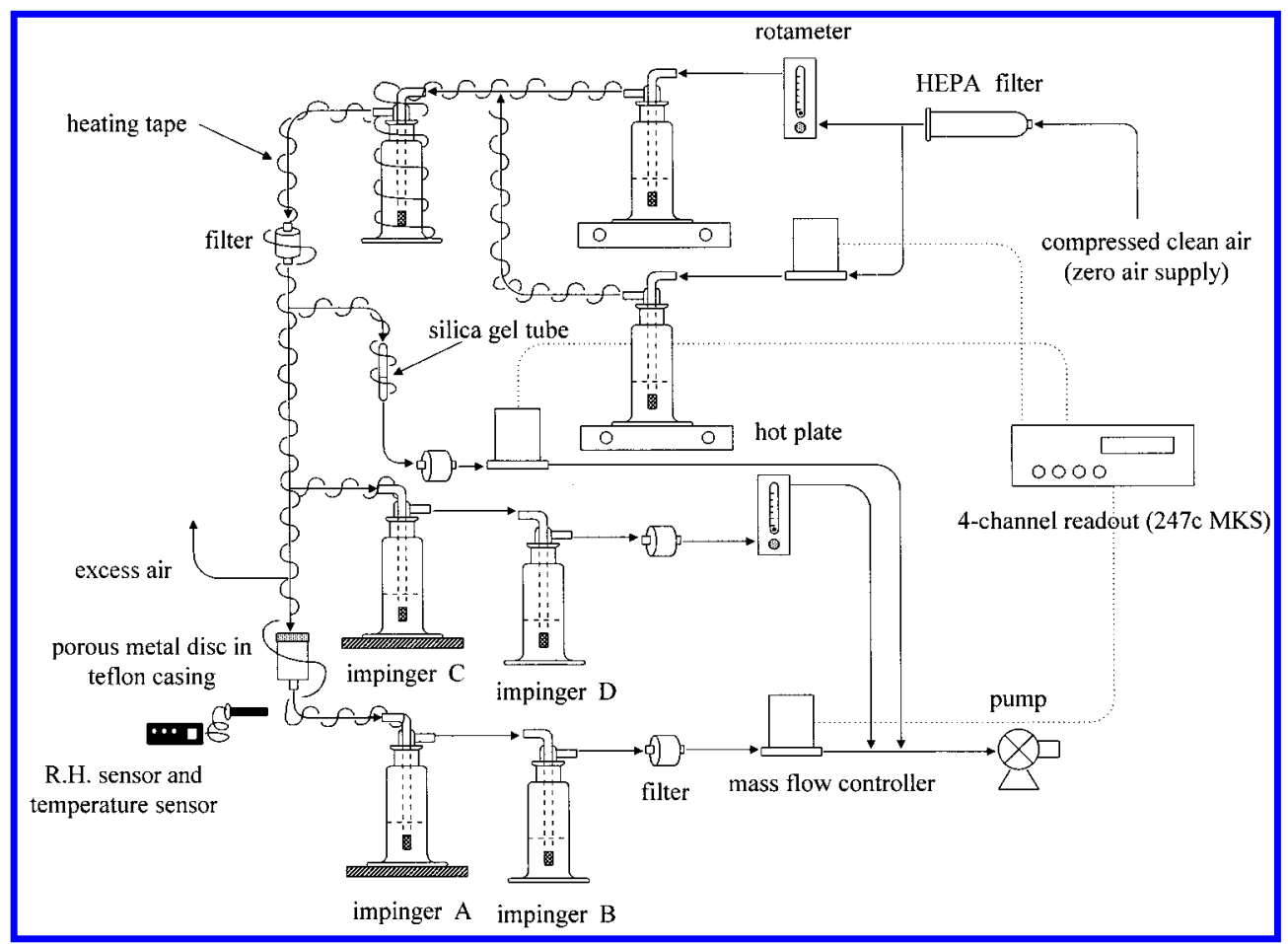

FIGURE 1. Test setup for measuring the gas collection and capacity of silica gel tube, impinger, and porous metal disk.

gel, impinger, and porous metal disk. The silica gel tubes contained two sections of washed silica gel (first section, 400 $\mathrm{mg}$; second section, $200 \mathrm{mg}$ ) while the impingers contained proper concentration of absorbing solutions $\left(0.01 \mathrm{~N} \mathrm{H}_{2} \mathrm{SO}_{4}\right.$ for ammonia and $0.1 \mathrm{~N} \mathrm{NaOH}$ for other acids). There were two impingers (impingers $\mathrm{A}$ and $\mathrm{B}$ ) behind the porous metal disk to measure the unabsorbed gas. Two different coating concentrations on the porous metal disks were used for the test. For acidic gases, $10 \mathrm{~mL}, 3$ or $5 \%$ (w/ v in $\mathrm{g} / \mathrm{mL}$ ) sodium carbonate, $1 \%(\mathrm{w} / \mathrm{v})$ glycerol in $1: 1$ (v/v) methanol/water solution was used. For ammonia gas, $10 \mathrm{~mL}$, 2 or $4 \%$ (w/v) citric acid in ethanol was used. After being coated, the porous metal disks were dried by passing nitrogen gas through it. After being sampled, the porous metal disk was extracted with distilled deionized water in a low-pressure chamber at $0.2 \mathrm{~atm}$ (14). The samples of the silica gel were prepared according to the procedure described in NIOSH Method 7903 (4).

The concentrations of the test gas collected on the porous metal disk (concentration $\mathrm{C}_{1}$ ) and its two subsequent impingers (impinger $A$, concentration $C_{2}$; impinger $B$, concentration $\mathrm{C}_{3}$ ), silica gel (first section, concentration $\mathrm{C}_{4}$; second section, concentration $C_{5}$ ), and impingers (first piece impinger $C$, concentration $C_{6}$; second piece impinger $D$, concentration $\mathrm{C}_{7}$ ) were determined by an ion chromatograph (model 4500i, Dionex Corp., CA). Thegas collection efficiency of the porous metal disk ( $\eta_{\mathrm{d}}, \%$ ), the first section of silica gel tube $\left(\eta_{\mathrm{s}}, \%\right)$, and the first impinger $\left(\eta_{\mathrm{i}}, \%\right)$ was calculated as

$$
\begin{gathered}
\eta_{\mathrm{d}}(\%)=\frac{\mathrm{C}_{1}}{\mathrm{C}_{1}+\mathrm{C}_{2}+\mathrm{C}_{3}} \times 100 \\
\eta_{\mathrm{s}}(\%)=\frac{\mathrm{C}_{4}}{\mathrm{C}_{4}+\mathrm{C}_{5}} \times 100 \\
\eta_{\mathrm{i}}(\%)=\frac{\mathrm{C}_{6}}{\mathrm{C}_{6}+\mathrm{C}_{7}} \times 100
\end{gathered}
$$

Concentrations of the test gases were almost the same between different sampling lines, which indicated that test gas generation system was steady. The differences were less than $5 \%$. In the sampling line of the porous metal disk, the concentrations $\left(C_{1}+C_{2}+C_{3}\right)$ were found to be $3.80 \pm 0.09$, $9.68 \pm 0.16$, and $6.05 \pm 0.02 \mathrm{ppm}$ (average \pm standard deviation) for $\mathrm{HNO}_{3}, \mathrm{HCl}$, and $\mathrm{HF}$, respectively. In comparison, concentrations for $\mathrm{HNO}_{3}, \mathrm{HCl}$, and $\mathrm{HF}$ found in the sampling line of silica gel $\left(C_{4}+C_{5}\right)$ were $3.91 \pm 0.10,10.20$ \pm 0.21 , and $6.02 \pm 0.01 \mathrm{ppm}$, respectively, and $3.89 \pm 0.08$, $9.77 \pm 0.07$, and $6.04 \pm 0.03$ ppm for impingers $\left(C_{6}+C_{7}\right)$, respectively. For $\mathrm{NH}_{3}$, they were $99.51 \pm 0.49$ and $101.30 \pm$ 0.86 ppm for porous metal disk $\left(C_{1}+C_{2}+C_{3}\right)$ and impingers $\left(\mathrm{C}_{6}+\mathrm{C}_{7}\right)$, respectively.

Thegascollection efficiency was measured at thesampling time of 1, 2, 3, and $4 \mathrm{~h}$. Each test was repeated 6-12 times to determine the precision of the experiment. Breakthrough time was defined when the collection efficiency was dropped below 95\%. Gascollection capacity, expressed in milligrams, was calculated by integrating the sampling air volume and test gas concentration until the breakthrough time.

Careful QA/ QC procedures were followed, and the results are shown in Table 1. The method detection limit (MDL) is expressed in terms of equivalent gas-phase concentration based on 8-h sampling at $2 \mathrm{~L} / \mathrm{min}$ for the porous metal disk, $1 \mathrm{~L} / \mathrm{min}$ for the impinger, and $0.2 \mathrm{~L} / \mathrm{min}$ for the silica gel tube. The MDL of all species for three samplers is typically less than 10 ppbv, which is much smaller than the test gas concentration, and the recovery efficiency is between 95 and $105 \%$.

\section{Results and Discussion}

Figure 2 shows the gas collection efficiencies of the porous metal disk, silica gel tube (first section), and impinger (first piece) for acidic and basic gases at different sampling times. Using 3\% sodium carbonate coating, the gas collection efficiencies of the porous metal disk are all $100 \%$ for $\mathrm{HNO}_{3}$ when the sampling time is less than 3.0 h, as shown in Figure 2a. That is, there is no $\mathrm{HNO}_{3}$ collected by either impinger $\mathrm{A}$ or impinger $\mathrm{B}$. The efficiency drops to $86.1 \pm 0.4 \%$ (average \pm standard deviation) at the sampling time of $4.0 \mathrm{~h}$. Increasing 
TABLE 1. Method Detection Limit and Recovery Efficiency of Samplers

\begin{tabular}{|c|c|c|c|c|c|c|c|}
\hline \multirow[b]{2}{*}{ sample } & \multirow[b]{2}{*}{$n^{c}$} & \multicolumn{3}{|c|}{ MDLa (ppbv) } & \multicolumn{3}{|c|}{ recovery $\left(\mathbf{S D}^{b}\right)(\%)$} \\
\hline & & $\begin{array}{c}\text { porous } \\
\text { metal disk }\end{array}$ & $\begin{array}{c}\text { silica } \\
\text { gel }\end{array}$ & impinger & $\begin{array}{c}\text { porous } \\
\text { metal disk }\end{array}$ & $\begin{array}{l}\text { silica } \\
\text { gel }\end{array}$ & impinger \\
\hline $\begin{array}{l}\mathrm{NO}_{3}^{-} \\
\mathrm{Cl}^{-} \\
\mathrm{F}^{-} \\
\mathrm{NH}_{4}{ }^{+}\end{array}$ & $\begin{array}{l}7 \\
7 \\
7 \\
7\end{array}$ & $\begin{array}{l}1.5 \\
4.0 \\
1.5 \\
8.1\end{array}$ & $\begin{array}{l}1.3 \\
2.9 \\
3.8\end{array}$ & $\begin{array}{l}0.5 \\
2.0 \\
4.8 \\
7.4\end{array}$ & $\begin{array}{r}95.7(0.4) \\
101.5(1.0) \\
103.6(2.2) \\
98.1(3.8)\end{array}$ & $\begin{array}{l}98.0(0.3) \\
94.1(0.9) \\
99.4(5.2)\end{array}$ & $\begin{array}{r}97.1(4.9) \\
101.2(1.8) \\
98.8(1.9) \\
100.3(2.0)\end{array}$ \\
\hline
\end{tabular}

${ }^{a} \mathrm{MDL}$, method detection limit, in equivalent gas-phase concentration, ppb by volume. ${ }^{b} \mathrm{SD}$, standard deviation. ${ }^{c} n$, number of samples.

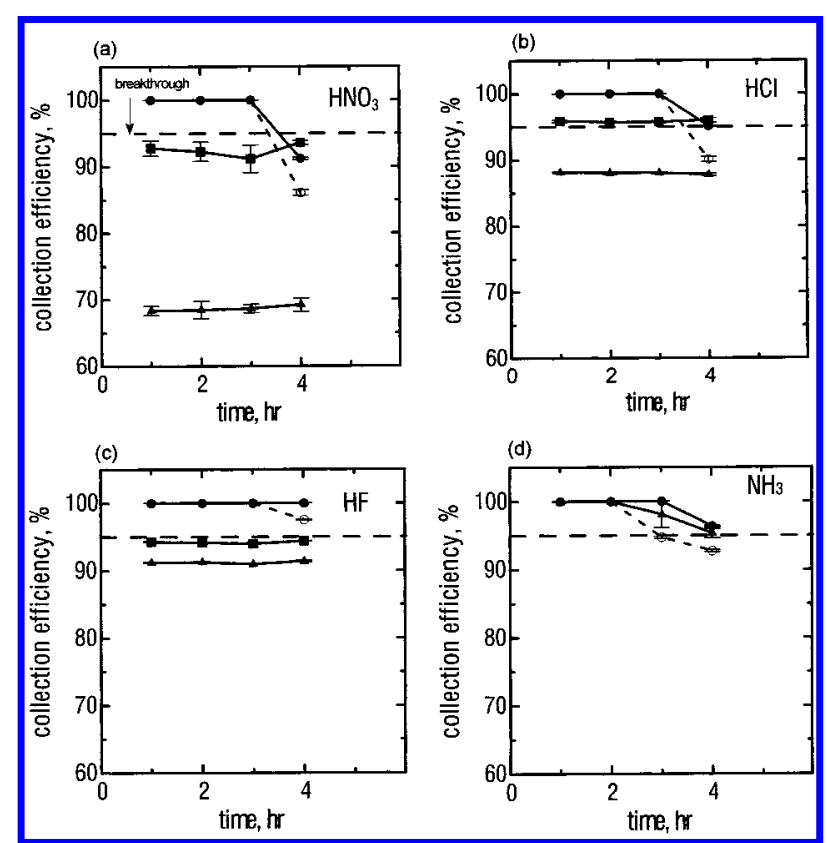

FIGURE 2. Gas collection efficiencies of (a) nitric acid, (b) hydrogen chloride, (c) hydrogen fluoride, and (d) ammonia gas sampled by coated porous metal disk, silica gel tube, and impinger versus sampling time. (Panels a-c) Porous metal disk with $5 \%$ sodium carbonate coating (solid circles), $3 \%$ sodium carbonate coating (open circles); silica gel (solid squares); impinger (solid triangles). (Panel d) Porous metal disk w ith $4 \%$ citric acid coating (solid circles), $2 \%$ citric acid coating (open circles); impinger (solid triangles).

the sodium carbonate concentration coated on the porous metal disk to $5 \%$, the gas collection efficiency is increased to $91.2 \%$ at the sampling time of $4 \mathrm{~h}$. The breakthrough time (time at which the collection efficiency drops to 95\%) is 3.1 $\mathrm{h}$, and thecorresponding gas collection capacity of the porous metal disk is cal culated to be $3.9 \mathrm{mg}$ for $\mathrm{HNO}_{3}$ at $5 \%$ coating concentration. In comparison, the collection efficiencies of the silica gel tube and impinger are $91.2-3.6 \%$ and $68.2-$ $8.7 \%$, respectively, during the $4.0-\mathrm{h}$ sampling time. The efficiencies are seen to be lower than those of porous metal disk.

Similar results are found for $\mathrm{HCl}$ and $\mathrm{HF}$ gases as seen in Figure 2b,c. The gas collection efficiencies of the porousmetal disk are all higher than those of silica gel tube, and those for the impinger are the lowest. Using 5\% sodium carbonate coating results in a better collection efficiency than 3\%coating for the porous metal disk at the sampling time of $4 \mathrm{~h}$, while the efficiencies are all $100 \%$ when thesamplingtime issmaller than $3 \mathrm{~h}$ for the disk with $3 \%$ or $5 \%$ coating. The breakthrough time is $3.2 \mathrm{~h}$, and the gas collection capacity of the porous metal disk is calculated to be $5.8 \mathrm{mg}$ for $\mathrm{HCl}$. The breakthrough time is greater than $4.0 \mathrm{~h}$, and the capacity for HF is calculated to be greater than $2.5 \mathrm{mg}$ for the disk with $5 \%$ coating concentration.
For both $\mathrm{HCl}$ and $\mathrm{HF}$, the gas collection efficiencies for silica gel tubes are close to $95 \%$ during 4-h sampling, while the corresponding collection efficiencies for the impingers are about $88 \%$ and $91 \%$ for $\mathrm{HCl}$ and $\mathrm{HF}$, respectively.

For ammonia, Figure $2 \mathrm{~d}$ shows that different citric acid coating concentrations also result in different $\mathrm{NH}_{3}$ collection efficiencies and capacities by the porous metal disk. Increasing the concentration of citric acid coating solution from $2 \%$ to $4 \%$ increases the efficiency at $4 \mathrm{~h}$ from $92.7 \%$ to $96.4 \%$, and the breakthrough time is increased from $3.0 \mathrm{~h}$ to greater than $4.0 \mathrm{~h}$. The corresponding collection capacity for $4 \%$ coating concentration is slightly greater than $33.6 \mathrm{mg}$. For the impinger, the breakthrough time is close to $4 \mathrm{~h}$.

The experimental data also show that if theconcentrations of both first and second sections of the silica gel or both the first and second impingers were added, the collection efficiencies would be close to $100 \%$ in all cases and at all sampling times. This indicates that the penetration of gas does occur through the first section of the silica gel or the first impinger. The reason for the breakthrough of the first silica gel maybe due to high humidity while that for the first impinger maybe due to the carryover of liquid particles to the second impinger. It is recommended that the concentrations of both first and second sections of the silica gel and first and second impingers be added together to determine accurate concentration values. For the porous metal disk, the concentration of coating solution is determined by the amount of gas species that needs to besampled. If the amount is much less than several milligrams, then it is possible to use $3 \%$ (sodium carbonate) or $2 \%$ (citric acid) coating for the acidic or ammonia gas, respectively.

\section{Acknowledgments}

The authors are thankful for the financial support of the Taiwan Institute of Occupational Safety and Health (IOSH) under Contract IOSH88-A105.

\section{Literature Cited}

(1) Franks, A. P.; Harper, P. J.; Bilo, M. L. Hazard. Mater. 1996, 51, $11-34$.

(2) Wyzga, R. E. Water, Air Soil Pollut. 1995, 85, 177-188.

(3) Suh, H. H.; Spengler, J. D.; Koutrakis, P. Environ. Sci. Technol. 1992, 26, 2507-2517.

(4) No. 7903. Manual of Analytical Methods, 4th ed.; National Institute for Occupational Safety and Health (NIOSH): Cincinnati, OH, 1994.

(5) Cassinelli, M. E.; Taylor, D. G. Am. Chem. Soc. Symp. Ser. 1981, No. 149, 137-152.

(6) Cassinelli, M. E. Am. Ind. Hyq. Assoc. 1986, 47, 219-224.

(7) No. 2401. Manual of Analytical Methods, 1st ed.; Institute of Occupational Safety and Health (Taiwan IOSH): Taiwan, 1994 (in Chinese).

(8) Ammonia in WorkplaceAtmosphere, Method ID-164; Inorganic Methods Evaluation Branch, U.S. Occupational Safety and Health Administration: Salt Lake City, UT, 1988.

(9) Certification Procedure of Sampling and Analysis Reference Methods for Hazardous Pollutants in Work Environments; Institute of Occupational Safety and Health (Taiwan IOSH): Taiwan, 1996; No. IOSH85-T-011 (in Chinese). 
(10) Ferm, M. Atmos. Environ. 1979, 13, 1385-1393.

(11) Possanzini, M.; Febo, A.; Liberti, A. Atmos. Environ. 1983, 17, 2605-2610.

(12) Pui, D. Y. H.; Lewis, C. W.; Tsai, C. J.; Liu, B. Y. H. L. Aerosol Sci. 1990, 24, 307-312.

(13) Koutrakis, P.; Sioutas, C.; Ferguson, S. T.; Wolfson, J. M. Environ. Sci. Technol. 1993, 27, 2497-2501.
(14) Wai, S. P.; Pui, D. Y. H.; Lee, C. T.; Liu, B. Y. H. L. Aerosol Sci. 1994, 25, 923-934.

Received for review December 5, 2000. Revised manuscript received March 2, 2001. Accepted March 8, 2001.

ES001943Z 